\title{
Accelerating Effect of Acetylene on the $\gamma$-Radiation-Induced Cross-Linking of Polyethylene
}

\author{
Hiroshi Mitsui, ${ }^{*}$ Fumio Hosor, ${ }^{*}$ and Tsutomu Kagiya** \\ *Japan Atomic Energy Research Institute, Takasaki Radiation Chemistry \\ Research Establishment, Takasaki, Gunma, Japan. \\ **Faculty of Engineering of Kyoto University, Kyoto, Japan.
}

(Received February 28, 1973)

\begin{abstract}
The $\gamma$-radiation-induced cross-linking of polyethylene was investigated in the presence of acetylene under an absolute pressure of $3 \mathrm{~kg} / \mathrm{cm}^{2}$ at $30-200^{\circ} \mathrm{C}$ with a dose rate of $1.1 \times 10^{5} \mathrm{rad} / \mathrm{hr}$. The weight of the polyethylene increased almost proportionally to the radiation dose, and the rate of the increase was larger at 30 and $90^{\circ} \mathrm{C}$ than at 150 and $200^{\circ} \mathrm{C}$. The gel fraction increased with rising irradiation temperature, passed through a maximum at around $105^{\circ} \mathrm{C}$, and thereafter decreased sharply to become almost constant above $150^{\circ} \mathrm{C}$. At temperatures below the melting temperature of polyethylene, the gel fraction was much higher than in vacuo. As a characteristic structural change, the formation of terminal vinyl unsaturation was observed, and the rate of the formation increased with the temperature. The formation of hydrogen and trans-vinylene unsaturation was little affected by acetylene. On the basis of these results, the role of acetylene in the $\gamma$-radiation-induced cross-linking of polyethylene was discussed from the view-point of the reaction mechanism.
\end{abstract}

KEY WORDS $\gamma$-Radiation / Cross-Linking / Polyethylene / Acetylene / Gel Fraction / Hydrogen Formation / Structural Change /

In the $\gamma$-radiation-induced polymerization of ethylene containing acetylene, it has been concluded $^{1,2}$ that the number of polymer chains formed is reduced by a reaction such as crosslinking caused by acetylene. The effect of acetylene on the $\gamma$-radiation-induced cross-linking of polyethylene has been presented in a patent literature, ${ }^{3}$ and we reported $^{4,5}$ briefly that the cross-linking is remarkably accelerated by acetylene which causes a chain reaction.

In this paper, the quantitative experimental results are examined for the gel fraction, hydrogen formation, and the changes in the weight and structure of polyethylene irradiated by $\gamma$ rays in the presence of acetylene at $30-200^{\circ} \mathrm{C}$ in comparison with the results in vacuo, ${ }^{6}$ and the role of acetylene in the $\gamma$-radiation-induced cross-linking of polyethylene is discussed from the view-point of the reaction mechanism.

\section{EXPERIMENTAL}

The reaction vessel, polyethylene, and the measurement methods of gel fraction, hydrogen and infrared spectra were the same as described in the previous paper. ${ }^{6}$ Commercially available acetylene (99.9\% pure) was used.

About $2 \mathrm{~g}$ of polyethylene was accurately weighed out into a reaction vessel, and evacuated to a pressure of $10^{-4} \mathrm{mmHg}$ at the reaction temperature for more than $1 \mathrm{hr}$. The vessel was then charged with acetylene to a pressure just above atmospheric pressure, and evacuated. After this operation was repeated seven times, the vessel was filled with acetylene to an absolute pressure of $3 \mathrm{~kg} / \mathrm{cm}^{2}$ at the reaction temperature, and irradiated by $\gamma$-rays from a 5000$\mathrm{Ci}{ }^{60} \mathrm{Co}$ with a dose rate of $1.1 \times 10^{5} \mathrm{rad} / \mathrm{hr}$. The irradiated polyethylene was evacuated overnight under reduced pressure at room temperature, and weighed.

The amount of hydrogen formation was corrected by subtracting the amount of hydrogen formed by the radiolysis of acetylene from the observed value. 


\section{RESULTS}

\section{Hydrogen Formation}

As shown in Table I, when polyethylene is irradiated in the presence of acetylene, the $G$ value of hydrogen formation $\left[G_{\mathrm{A}}\left(\mathrm{H}_{2}\right)\right]$ is practically equal at each temperature to the one in vacuo $\left[G_{\mathrm{V}}\left(\mathrm{H}_{2}\right)\right]$, and tends to increase gradually with the rise of irradiation temperature. The activation energy is given as $0.5 \mathrm{kcal} / \mathrm{mol}$ from the Arrhenius plot of $G_{A}\left(H_{2}\right)$. The value is approximately equivalent to the one of 0.4 $\mathrm{kcal} / \mathrm{mol}$ in vacuo. ${ }^{6}$

From the results, it can be concluded that hydrogen formation is little affected by acetylene.

Table I. $G$-values

\begin{tabular}{lcccc}
\hline \multirow{2}{*}{$G$-value } & \multicolumn{4}{c}{ Temp, ${ }^{\circ} \mathrm{C}$} \\
\cline { 2 - 5 } & 30 & 90 & 150 & 200 \\
\hline$G_{\mathrm{A}}\left(\mathrm{H}_{2}\right)$ & 2.66 & 3.34 & 3.41 & 3.54 \\
$G_{\mathrm{A}}\left(-\mathrm{C}_{2} \mathrm{H}_{2}\right)$ & 54.6 & 60.3 & 24.6 & 24.8 \\
$G_{\mathrm{A}}(\mathrm{X})$ & 7.64 & 9.06 & 5.48 & 5.69 \\
$G_{\mathrm{A}}(\mathrm{S})$ & 8.44 & 8.95 & 8.22 & 8.35 \\
$G_{\mathrm{A}}(\mathrm{Vi})$ & 7.26 & 7.77 & 11.36 & 12.30 \\
\hline$G_{\mathrm{V}}\left(\mathrm{H}_{2}\right)^{\mathrm{b}}$ & 2.79 & 3.27 & 3.18 & 3.64 \\
$G_{\mathrm{V}}(\mathrm{X})^{\mathrm{b}}$ & 0.76 & 1.44 & 4.55 & 5.06 \\
$G_{\mathrm{V}}(\mathrm{S})^{\mathrm{b}}$ & 0.77 & 1.34 & 5.87 & 6.51 \\
\hline
\end{tabular}

a Subscripts of $\mathrm{A}$ and $\mathrm{V}$ are used to designate the $G$-values in the presence of acetylene and in vacuo, respectively.

b $G$-values in vacuo are taken from the paper cited in ref 6 .

\section{Weight Change}

The weight of polyethylene irradiated in the presence of acetylene increases almost linearly with the radiation dose (Figure 1). The rate of increase slightly accelerates with rising irradiation temperature from 30 to $90^{\circ} \mathrm{C}$, and decreases markedly from 90 to $150^{\circ} \mathrm{C}$ to become almost constant above $150^{\circ} \mathrm{C}$.

Since the weight of polyethylene remains essentially unaltered by the irradiation in vacuo, and bulk polymerization of acetylene hardly occurs under the conditions investigated, it seems reasonable to consider that the increase in the weight is brought about by the addition reaction

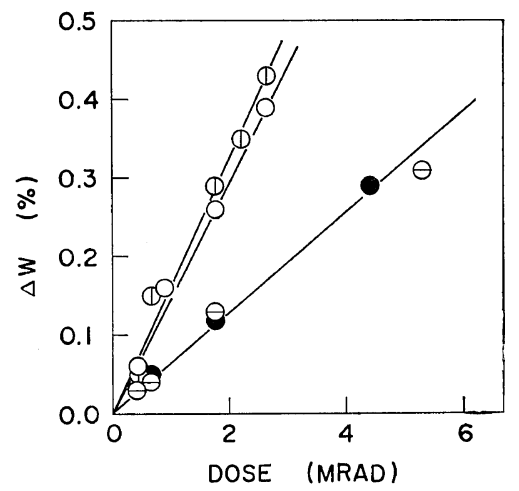

Figure 1. Increase in the weight of polyethylene $(\Delta W)$ irradiated in the presence of acetylene: pressure, $3 \mathrm{~kg} / \mathrm{cm}^{2}$ abs; dose rate, $1.1 \times 10^{5} \mathrm{rad} / \mathrm{hr}$; $\bigcirc$, $30^{\circ} \mathrm{C}$; (1), $90^{\circ} \mathrm{C}$; $\ominus, 150^{\circ} \mathrm{C}$;, $200^{\circ} \mathrm{C}$.

of acetylene to polyethylene.

The $G$-values of reacted acetylene $\left[G_{\mathrm{A}}\left(-\mathrm{C}_{2} \mathrm{H}_{2}\right)\right]$ are calculated as given in Table $\mathrm{I}$ from the slopes of the straight lines in Figure 1.

\section{Gel Fraction}

The relation between the gel fraction and irradiation temperature is shown in Figure 2. In this figure, the gel fractions in vacuo are plotted by using the values reported in the previous paper. ${ }^{6}$

Figure 2 shows that the gel fraction in the

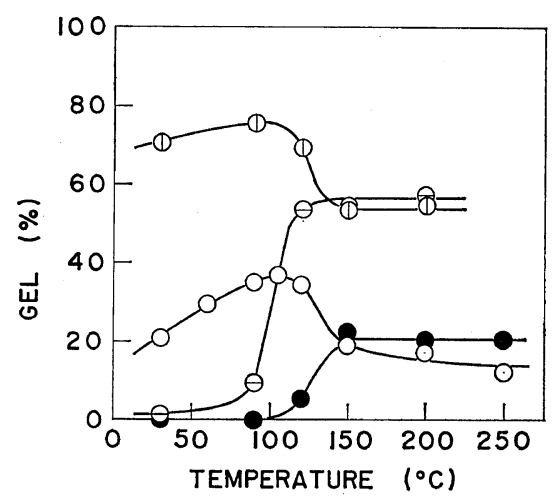

Figure 2. Effect of temperature on the gel fraction of polyethylene irradiated in vacuo and in the presence of acetylene under a pressure of $3 \mathrm{~kg} / \mathrm{cm}^{2}$ abs: dose rate, $1.1 \times 10^{5} \mathrm{rad} / \mathrm{hr}$;, $0.44 \mathrm{Mrad} ; \ominus, 1.76$ Mrad; in vacuo taken from the work cited in ref 6; $\bigcirc, 0.44 \mathrm{Mrad}$; (1), $1.76 \mathrm{Mrad}$ in the presence of acetylene (present work). 
presence of acetylene increases with rising temperature, passes through a maximum at around $105^{\circ} \mathrm{C}$, and thereafter decreases markedly to become almost constant above $150^{\circ} \mathrm{C}$. On the other hand, in vacuo, the gel fraction increases with the temperature to become almost constant above $150^{\circ} \mathrm{C}$.

The gel fraction is significantly greater when the irradiation is carried out in the presence of acetylene than in vacuo at temperatures below $120^{\circ} \mathrm{C}$, which corresponds approximately to the melting temperature of polyethylene used. On the contrary, the gel fraction above $150^{\circ} \mathrm{C}$ is somewhat lower in the presence of acetylene than in vacuo.

Since the initial molecular-weight distribution of polyethylene used is considered to be random, it has been suggested ${ }^{6}$ that the $G$-values of crosslinking $[G(\mathrm{X})]$ and main-chain scission $[G(\mathrm{~S})]$ can be calculated by using eq 1 derived by Charlesby and Pinner. ${ }^{7}$

$$
s+s^{1 / 2}=\frac{G(\mathrm{~S})}{2 G(\mathrm{X})}+\frac{1.602 \times 10^{-18} N_{\mathrm{A}}}{G(\mathrm{X}) M_{w} r}
$$

where $s$ is the sol fraction, which is given as $(1-g)$ from the gel fraction $(g)$ obtained experimentally, $N_{\mathrm{A}}$ is the Avogadro's number, $M_{w}$ is the original weight-average molecular weight, and $r$ is the radiation dose (in Mrad).

When polyethylene is irradiated in the presence of acetylene, it can be assumed that the change of the molecular weight in the course of the irradiation is little affected by acetylene, since the increase in the weight of polyethylene due to the reacted acetylene is less than $0.5 \mathrm{wt} \%$ as shown in Figure 1. The $G$-values of crosslinking and main-chain scission in the presence of acetylene $\left[G_{A}(\mathrm{X})\right.$ and $\left.G_{A}(\mathrm{~S})\right]$, therefore, can be calculated by using eq 1 .

The values of $G_{A}(X)$ and $G_{A}(S)$ are listed in Table $I$ with the ones in vacuo $\left[G_{V}(\mathrm{X})\right.$ and $\left.G_{\mathrm{V}}(\mathbf{S})\right]^{6}{ }^{6}$

\section{Infrared Spectra}

Figure 3 shows the infrared spectra of nonirradiated polyethylene (polymer A) and of polyethylenes irradiated at $30^{\circ} \mathrm{C}$ in vacuo (polymer B) and in the presence of acetylene (polymer $\mathrm{C}$ ).

In the spectrum of polymer $\mathrm{C}$, the absorption bands assigned to terminal vinyl unsaturation

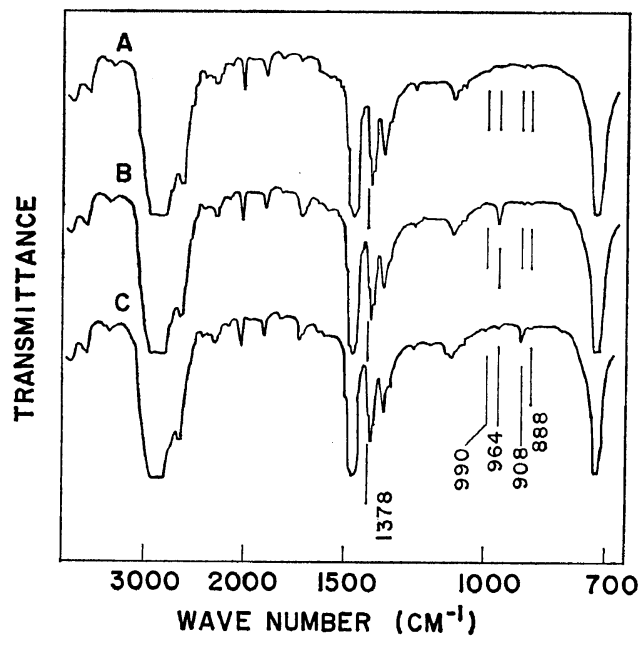

Figure 3. Infrared spectra of polyethylene: A, unirradiated; B, irradiated to $22 \mathrm{Mrad}$ in vacuo; $\mathrm{C}$, irradiated to $2.64 \mathrm{Mrad}$ in the presence of acetylene under a pressure of $3 \mathrm{~kg} / \mathrm{cm}^{2}$ abs; temp, $30^{\circ} \mathrm{C}$; dose rate, $1.1 \times 10^{5} \mathrm{rad} / \mathrm{hr}$.

( 990 and $908 \mathrm{~cm}^{-1}$ ) increase as well as the band near $964 \mathrm{~cm}^{-1}$ ascribed to trans-vinylene unsaturation, while only the peak near $964 \mathrm{~cm}^{-1}$ increases in the spectrum of polymer $B$. The change in the absorption bands assigned to the triple bond $\left(2260-2190\right.$ and $\left.2140-2100 \mathrm{~cm}^{-1}\right)$, conjugated double bond $\left(1600 \mathrm{~cm}^{-1}\right)$, vinylidene unsaturation $\left(888 \mathrm{~cm}^{-1}\right)$, and methyl group (1378 $\mathrm{cm}^{-1}$ ) is not observed in either spectra of polymer $B$ or C.

From the results, the structural change of polyethylene irradiated in the presence of acetylene is characterized by the formation of terminal vinyl unsaturation.

\section{Contents of Double Bonds and Methyl Group}

As shown in Figures 4 and 5, the content of terminal vinyl and trans-vinylene unsaturations increases almost linearly with the radiation dose. The rate of formation of terminal vinyl unsaturation increases with the irradiation temperature, while that of trans-vinylene unsaturation is almost independent of the temperature.

The content of vinylidene unsaturation and methyl group is little affected by the irradiation in the presence of acetylene at any of the temperatures investigated, while the methyl group has been reported ${ }^{6}$ to form in vacuo at 150 and $200^{\circ} \mathrm{C}$. 


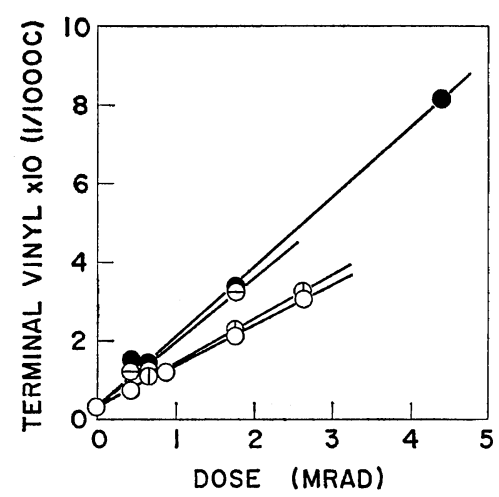

Figure 4. Content of terminal vinyl unsaturation of polyethylene irradiated in the presence of acetylene: reaction conditions same as given for Figure 1.

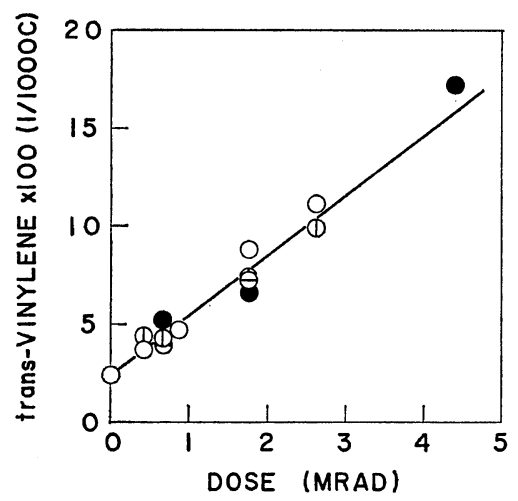

Figure 5. Content of trans-vinylene unsaturation of polyethylene irradiated in the presence of acetylene: reaction conditions same as given for Figure 1.

The $G$-values of the formation of terminal vinyl unsaturation $\left[G_{A}(\mathrm{Vi})\right]$ are calculated as shown in Table I from the slopes of the straight lines in Figure 4.

From the slope of the straight line in Figure 5 , the $G$-value of the formation of trans-vinylene unsaturation $\left[G_{A}(t-\mathrm{V})\right]$ is given to be 2.11 , which is almost equivalent to the mean $G$-value of 1.95 in vacuo. $^{6}$ Accordingly, it can be concluded that the formation of trans-vinylene unsaturation is scarcely affected by acetylene.

\section{DISCUSSION}

Role of Acetylene

When polyethylene is irradiated by $\gamma$-rays, the primary radiation-chemical reactions are represented as follows:

$$
\begin{gathered}
-\mathrm{CH}_{2}-\longrightarrow-\dot{\mathrm{C}} \mathrm{H}-+\mathrm{H} . \\
-\mathrm{CH}_{2}-\mathrm{CH}_{2}-\longrightarrow-\dot{\mathrm{C}} \mathrm{H}_{2}+\dot{\mathrm{C}} \mathrm{H}_{2}-
\end{gathered}
$$

Since the formation of hydrogen and transvinylene unsaturation is little affected by acetylene as described above, these must be formed in the presence of acetylene by the same mechanism as in vacuo, ${ }^{6}$ that is, hydrogen is formed by the reactions of eq 4 and 5 after the reaction of eq 2, and trans-vinylene unsaturation by eq 5 .

$$
\begin{gathered}
-\mathrm{CH}_{2}-+\mathrm{H} \cdot \longrightarrow-\dot{\mathrm{C}} \mathrm{H}-+\mathrm{H}_{2} \\
-\dot{\mathrm{C}} \mathrm{H}-\mathrm{CH}_{2}-+\mathrm{H} \cdot \longrightarrow-\mathrm{CH}=\mathrm{CH}-+\mathrm{H}_{2}
\end{gathered}
$$

From the mechanism, the reactions within polyethylene, such as cross-linking and addition reaction of acetylene to the polymer, can be expected to be induced by the polymer radicals $(P \cdot)$ resulting from the reactions of eq $2-5$. By assuming the stationary state with respect to the concentration of hydrogen radical in the reactions of eq $2-5$, the over-all $G$-value for the formation of the polymer radicals $\left[G_{A}(P \cdot)\right]$ is given as eq 6 .

$$
G_{\mathrm{A}}(\mathrm{P} \cdot)=2\left\{G\left(\mathrm{H}_{2}\right)-G(t-\mathrm{V})+G(\text { eq } 3)\right\}
$$

The reaction of eq 3 may be little affected by acetylene, and the main-chain scission in vacuo only occurs by this reaction. ${ }^{6}$ The $G$-value of the reaction of eq 3 in the presence of acetylene, therefore, can be assumed to be equal to $G_{\mathrm{V}}(\mathbf{S})$. The values of $G_{A}(P \cdot)$ are calculated as shown in Table II from eq 6 by using $G_{A}\left(\mathrm{H}_{2}\right), G_{A}(t-\mathrm{V})$, and $G_{\mathrm{V}}(\mathbf{S})$.

Table II. $G_{\mathrm{A}}(\mathrm{P} \cdot)$ and $G_{\mathrm{A}}\left(-\mathrm{C}_{2} \mathrm{H}_{2}\right) / G_{\mathrm{A}}(\mathrm{P} \cdot)$

\begin{tabular}{rrc}
\hline Temp, ${ }^{\circ} \mathrm{C}$ & $G_{\mathrm{A}}(\mathrm{P} \cdot)$ & $G_{\mathrm{A}}\left(-\mathrm{C}_{2} \mathrm{H}_{2}\right) / G_{\mathrm{A}}(\mathrm{P} \cdot)$ \\
\hline 30 & 2.64 & 20.7 \\
90 & 5.14 & 11.7 \\
150 & 14.34 & 1.7 \\
200 & 15.88 & 1.6 \\
\hline
\end{tabular}

The ratio of $G_{\Delta}\left(-\mathrm{C}_{2} \mathrm{H}_{2}\right)$ to $G_{\Delta}(P \cdot)$ gives the average number of acetylene molecules reacted for each polymer radical formed through the reactions of eq 2-5. The values of $G_{A}\left(-C_{2} \mathrm{H}_{2}\right)$ / $G_{A}(P \cdot)$ are beyond unity at $30-200^{\circ} \mathrm{C}$ as shown 
in Table II. This indicates that the addition reaction of acetylene to polyethylene takes place successively. In addition, Table I shows that $G_{A}(X)$ and $G_{A}(S)$ at each temperature are higher than $G_{\nabla}(X)$ and $G_{V}(S)$, respectively.

Accordingly, when the irradiation is carried out in the presence of acetylene, it can be concluded that both the cross-linking and mainchain scission are accelerated in the course of the successive addition reaction of acetylene to

polyethylene, that is, a kind of chain reaction induced by acetylene.

Mechanism of Chain Reaction in Solid Polyethylene

The proposed chain mechanism induced by acetylene can be represented by eq $7-16$.

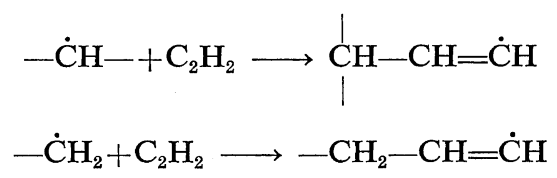

According to the discussion in the preceding section, the chain reaction induced by acetylene may be initiated by the addition reactions of acetylene to the side-chain (- $\dot{\mathrm{C}} \mathrm{H}-$ ) and mainchain $\left(-\dot{\mathrm{C}} \mathrm{H}_{2}\right)$ polymer radicals resulting from the reactions of eq $2-5$, that is, the reactions of eq 7 and 8 .

By using the method described in the preceding paper, ${ }^{6}$ the bond dissociation energies of $\mathrm{C}-\mathrm{C}$ bonds in the polymer radical formed by the reaction of eq 7 are calculated as follows (in $\mathrm{kcal} / \mathrm{mol}$ ):

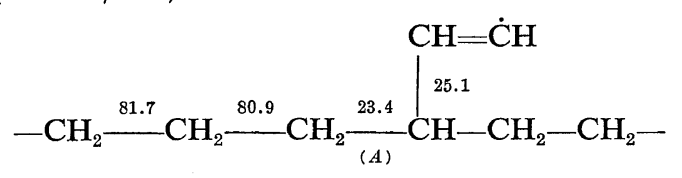

The result indicates that the $\mathrm{C}-\mathrm{C}$ bond of Aposition is easily severed as represented by the reaction of eq 9 . The two polymer radicals formed by this reaction are enclosed in a FrankRabinowitch "cage," and consequently are likely to react with each other.

In the main-chain polymer radical formed by the reaction of eq 9 , the $\mathrm{C}-\mathrm{H}$ bond of the closest methylene group for the radical end in the same molecule may be easily broken, because the bond dissociation energy of this bond is calculated to be $36.1 \mathrm{kcal} / \mathrm{mol}$. In addition, the relationship of eq 17 is found from Table I to hold approximately at 30 and $90^{\circ} \mathrm{C}$.

$$
G_{\mathrm{V}}(\mathrm{S})=G_{\mathrm{A}}(\mathrm{S})-G_{\mathrm{A}}(\mathrm{Vi})
$$


This relationship corresponds to the formation of one terminal vinyl unsaturation for each main-chain scission caused by acetylene. The disproportionation of eq 10 , therefore, may be the most probable reaction to occur after the reaction of eq 9.

When polyethylene is irradiated in the presence of acetylene, no polyene unsaturation, triple bond, and methyl group formation is observed as described before. The trans-vinylene unsaturation is formed by the reaction of eq 5 . In addition, it has been concluded ${ }^{1}$ that the growing chain radical having an acetylene end hardly reacts with acetylene in the $\gamma$-radiationinduced polymerization of ethylene containing acetylene.

These results indicate that the recombination and disproportionation occur little between the polymer radicals having acetylene ends, and between the radical and the side-chain or mainchain polymer radical, and that the addition reaction of acetylene to the polymer radical having an acetylene end seldom occurs.

On the basis of the results, the polymer radical having an acetylene end formed by the reactions of eq 7,8 , and 10 can be assumed to react directly with the methylene group of polyethylene as represented by the hydrogen transfer reactions of eq 11 and 12 .

Table I shows that $G_{\mathrm{A}}\left(-\mathrm{C}_{2} \mathrm{H}_{2}\right)$ is much higher than $G_{\mathrm{A}}(\mathrm{Vi})$ at all the temperatures investigated. The result suggests that the occurrence of the addition reactions of eq 13 and 14 between the terminal vinyl unsaturation and the side-chain polymer radical formed by the reactions of eq 11 and 12 , due to which the unsaturation disappears.

The side-chain polymer radical formed by the reactions of eq 11-14 may react with acetylene by the addition reaction of eq 7 , because the polymer radical is considered to possess the same reactivity as the side-chain polymer radical formed by the reactions of eq 2 and 4 . The addition reaction is followed by the reactions of eq 11 or the ones of eq 9,10 , and 12 . The reactions of eq 11 and 12 are further followed by the reactions of eq 13 and 14 in some cases, respectively.

The reactions of eq 7 and 9-14 may proceed successively until the side-chain polymer radical formed by the reactions of eq 11-14 disappears due to the cross-linking of eq 15 or to the endlinking of eq 16.

Since the segmental motion of solid polyethylene is greatly restrained, it seems reasonable to consider that the terminal vinyl unsaturation and side-chain polymer radical formed by the hydrogen transfer reactions of eq 11 and 12 disappear nearly quantitatively due to the mutual addition reactions of eq 13 and 14 . The terminal vinyl unsaturation in solid polyethylene, therefore, can be considered to form mainly by the disproportionation of eq 10 to occur after the main-chain scission of eq 9 .

As a result of these considerations, when solid polyethylene is irradiated in the presence of acetylene, it can be concluded that the gel formation is markedly accelerated by the cross-linking of eq 13 and the end-linking of eq 14 in the course of two chain reactions induced by acetylene, which consist of the reactions of eq 7 , 11 , and 13, and eq 7, 9, 10, 12, and 14 .

\section{Mechanism of Chain Reaction in Molten Poly- ethylene}

As described above, the gel fraction above $150^{\circ} \mathrm{C}$ is somewhat lower in the presence of acetylene than in vacuo (Figure 2). In addition, Table I shows that the decrease in $G_{A}(S)$ at $90-150^{\circ} \mathrm{C}$ is very small, and a significant difference exists between $G_{\mathrm{A}}(\mathrm{S})$ and $G_{\mathrm{V}}(\mathrm{S})$ at 150 and $200^{\circ} \mathrm{C}$. The results can be attributed to the main-chain scission of eq 9 in the course of the chain reaction induced by acetylene.

Table I also shows that the relationship of eq 17 can not apply at 150 and $200^{\circ} \mathrm{C}$, because $G_{\mathrm{A}}(\mathrm{Vi})$ is higher than $G_{\mathrm{A}}(\mathrm{S})$, though $G_{\mathrm{A}}(\mathrm{S})$ is higher than $G_{\mathrm{V}}(\mathrm{S})$. In addition, the terminal vinyl unsaturation and side-chain polymer radical formed by the hydrogen transfer reactions of eq 11 and 12 may diffuse easily within the reaction system at high temperatures where polyethylene is in the molten state.

The terminal vinyl unsaturation in molten polyethylene, therefore, can be expected to be formed by the reactions of eq 11 and 12 , besides the disproportionation of eq 10 to occur after the main-chain scission of eq 9. When the terminal vinyl unsaturation is formed by the reactions of eq 11 and 12, the cross-linking of eq 13 and the end-linking of eq 14 are blocked, 
resulting in the decrease of $G_{\mathrm{A}}(\mathrm{X})$ and the difference between $G_{\mathrm{A}}\left(-\mathrm{C}_{2} \mathrm{H}_{2}\right)$ and $G_{\mathrm{A}}(\mathrm{Vi})$ as can be seen in Table I.

On the basis of these considerations, when molten polyethylene is irradiated in the presence of acetylene, it can be suggested that the additional two chain reactions consisting of the reactions of eq 7 and 11, and eq 7, 9, 10, and 12 take place with the two chain reactions supposed to occur in solid polyethylene.

\section{Life of Chain Reaction}

According to the mechanism proposed above, the life of chain reaction induced by acetylene can be evaluated by the ratio of $G_{A}\left(-\mathrm{C}_{2} \mathrm{H}_{2}\right)$ / $G_{A}(P \cdot)$ given in Table II. The marked decrease in the ratio at 150 and $200^{\circ} \mathrm{C}$ indicates the remarkable decrease in the life of chain reaction in molten polyethylene as compared with the one in the solid polymer.

In the previous paper, ${ }^{6}$ the $G$-values of the reactions of eq 15 and 16 in vacuo have been reported to increase at 150 and $200^{\circ} \mathrm{C}$. The remarkable decrease in the life of chain reaction in molten polyethylene, therefore, can be ascribed to the increase in the rates of the reactions of eq 15 and 16 , by which the chain reactions induced by acetylene are terminated.

\section{REFERENCES}

1. H. Mitsui, F. Hosoi, M. Hagiwara, and T. Kagiya, J. Polym. Sci., Part A-1, 6, 2881 (1968).

2. H. Mitsui, F. Hosoi, and T. Kagiya, ibid., Part A-1, 7, 2575 (1969).

3. Toyo Rayon Co., Ltd., France Patent, 1392150 (1965).

4. H. Mitsui, F. Hosoi, and T. Kagiya, "Dai 9 Kai Nihon Rajioaisotōpukaigi Hōbunshū (Proceedings of the 9th Japan Conference on Radioisotopes)," Japan Atomic Industrial Forum, Inc., Tokyo, 1969, p 203.

5. H. Mitsui, F. Hosoi, and T. Kagiya, Polymer J., 3, 108 (1972).

6. H. Mitsui, F. Hosoi, and T. Kagiya, ibid., 4, 79 (1973).

7. A. Chapiro, "Radiation Chemistry of Polymeric Systems," Interscience Publishers, New York, N.Y., 1962, p 385. 